\title{
Chapter 21 \\ Healthy Healthcare Starts \\ with Energized and Vital Professionals: \\ The Human Factor at Work. A Case \\ Study at Radboud University Medical \\ Center Nijmegen
}

\section{Peter Loozen}

\begin{abstract}
This essay exposes an indispensable element for explorers and travellers on the road towards Healthy Healthcare: the human factor at work. The text provides some theoretical backgrounds, but mainly gives a comprehensive description of how the Radboud university medical center in the Netherlands invested in creating maximum vitality in an environment where workers feel energized and motivated. The Dutch Radboud university medical center (11,000 workers) introduced an innovative, person-oriented approach that supports healthy choices by using four perspectives. These are the perspectives from the individual worker, the supervisor, the team and the whole organization. Thus, a rich coexistence of self-direction and supportive group- and organizational interference starts to boost customization, leading to new solutions on different levels. A must read for those who believe vitality and wellbeing in large organizations is a multidimensional concept rather than an individual responsibility.
\end{abstract}

Keywords Human factor at work • Vitality • Radboud university medical center • Personalized and innovative

Box 21.1

"Working in healthcare means that you have to deliver peak performance every day. Our healthcare professionals, researchers, and lecturers are always willing to go above and beyond what is expected. However, this enthusiasm also has its limits. After all, our sector features a stressful workload and a growing number of vacancies. We are constantly faced with the necessary changes that come with innovation, digitization, and regulation. Furthermore, we work longer hours than most, often combined with informal care outside of the workplace. As a result, absenteeism in the healthcare is higher than in other sectors. These are the challenges we are currently facing. At Radboud university medical

P. Loozen $(\bowtie)$

Nijmegen, The Netherlands

e-mail: Peter.Loozen@ radboudumc.nl

L. T. Løvseth and A. H. de Lange (eds.), Integrating the Organization of Health Services, 
center in Nijmegen, over 11,000 people work in healthcare, education, and research. It is essential that we keep a close eye on our patients, but we also need to look out for each other as colleagues and staff. It is for this reason that we began asking ourselves the following questions several years ago: How do we retain the human factor at work? Are we still seeing the people behind the professionals?

Our greatest asset is the people who provide the healthcare. Excellent healthcare requires healthy professionals. In other words: how can we ensure vitality within our organization and create an environment where people feel energized and motivated?"

-P Loozen, Senior policy advisor HR

\subsection{The Human Factor}

A "one size fits all" approach or Human resource strategy does not fit our diverse group of healthcare staff. After all, each generation and staff member have different needs. An older employee with three years left until retirement is focused on working towards their pension at the right speed, while a young physician training in a specialization might still be learning how to balance their long workdays alongside a new family. A nurse who is also an informal caregiver faces challenges that are entirely different from those of a supervisor who juggles the schedules of 50 colleagues every week and must ensure that everyone is comfortable and vital in the workplace.

To ensure that employees thrive at work and enjoy it, all these levels or pillars need to be in harmony or balance (just like the Healthy healthcare concept suggests in Chap. 1 of this book). To ensure workers vitality some issues can be resolved individually, while others might require the involvement of a manager, a team that readily engages in discussion, the possibility for flexibility in scheduling work, and an organization that understands the importance of the human factor.

\subsection{Listening}

Focusing on workers vitality we initially started by listening instead of talking. The Executive Board took the initiative to speak with employees. What do you need as an individual? What about a team? This was where our search began. We approached the process from four perspectives:

- the individual,

- the supervisor,

- the team, 
- and the organization.

The talks that were held during this phase revealed the places where we should start looking and these led us to ideas and solutions. Sometimes the HR department initiated them, but often, the answers came from the professionals themselves. One example of this involved our colleagues who work in the night shifts in the ICU. They wanted to improve their fitness during these night shifts and wanted to avoid physical problems, such as feeling bloated, diarrhoea, and headaches they even sometimes experienced. They came up with the idea of taking short, refreshing powernaps during the night.

As an organization, we supported this idea by setting up rooms with relaxation chairs and dimmed lighting. We also adjusted the food provided in order to prevent a glucose spike during the night. Finally, everyone was given orange-tinted glasses before they left to go home. These glasses prevent melatonin levels from declining because of the daylight. This allows the night-shift employees to fall asleep more quickly and deeply once they arrive home. Not only does it improve their vitality, but we are also convinced that it enables them to provide better healthcare. Less fatigue means a lower risk of error.

\subsection{Fit Healthcare Professionals}

Another example is the Healthy Professionals program, an initiative started by the head of the Surgery department. People work in small teams to increase their stamina. How do you handle your energy and recovery time? The secret lies in the combination of adequate exercise, healthy food, and personal/professional development. However, attention is also given to spirituality and the balance between the body and mind. This is not a one-time meeting full of well-intentioned recommendations. It is a six-month program that alternates between training days and individual coaching in order to enable participants to build the habits of a healthy lifestyle. The goal is to take action to achieve the things that you want. As a participant in the program, you will be given three invitations that you can share with your colleagues. This is not an imposed, mandatory program: the decision to participate is entirely up to the staff member. Intrinsic motivation is a compulsory for behavioural change.

Over 400 people have since taken part in the program. The goal is 3000 . By doing this, we hope that people feel fitter, more energized and that absenteeism drops in a sector with a rate $5 \%$ higher than average. Not only does such a program have a positive impact on the participants, but it also benefits their partners and families, which is in keeping with our desire, as a university medical center, to have an impact on society. Not to mention that it also helps our patients. First and foremost, we anticipate that employees will be healthier and will, therefore, call in sick less frequently. We also believe that a nurse or physician who makes recommendations for a healthy lifestyle based in their own experiences and enthusiasm will be more 
convincing. After all, healthcare is not only about curing illnesses: the goal is to prevent them.

\subsection{A Broad Palette}

The power behind working on vitality lies in the level of customization. Solutions must be integrated seamlessly based on the needs of an individual employee or team. The question is always the same:

"What do you need?" Over time, we have developed a broad palette of options that can be used to support people: from the "generational meetings" and self-scheduling options for staff members to a curriculum for physicians in residence (AIOS) on topics such as the doctors of the future, leadership, healthcare expenses, and balance. This curriculum was initiated by the AIOS themselves. An initiative like this is valuable and effective, because it was devised by the target group. Another example is the peer support that the medical specialists offer each other. A pulmonologist and neurologist took the initiative to set up discussions in order to assist other specialists in dealing with pressure, making choices, or rediscovering job satisfaction.

We also organize a week dedicated to vitality every year. Several workshops and lectures are provided during this week. Vitality week is also an excellent time to test our ideas: is a workshop meeting a specific demand? The workshop on menopausal symptoms drew so many attendees that we made it a permanent part of our program. Vitality is even evident in our buildings. We encourage people to take the stairs. At the top of the steps, you can see how many calories you burned by taking the stairs instead of the elevator. It is vitality with a playful spin.

One of the four vitality perspectives is that of the supervisor. They play a key role in our organization. Supervisors are responsible to continuously maintain a balance between healthcare consistency, education and research, team health, and operational management. As such, we have developed a module specifically for supervisors. How can you create win-win-win situations? These are solutions that are not only good for the employee and supervisor, but also for the whole team.

These types of ideas require the investment of time and money. At Radboud university medical center, we have therefore implemented several initiatives in place to improve the quality of healthcare, education, and research. For example, we have "Hotspots", the vehicles for social innovation. The concept behind these hotspots is simple: the people on the work floor often know best when it comes to how patient care, education, and research can be improved. We do not bog down these ideas with lists of criteria that they have to meet, which means that they are given a fair chance. Our approval process is approachable and accessible. We feel that it is important for ideas to be applicable to other teams and departments, and we encourage working in a team. The team that submits the idea will receive financial or people-based support in developing it. In this way, Hotspots reflect how we operate at Radboud university medical center: we promote ownership by holding people accountable, while also providing assistance. 


\subsection{Personalized Healthcare}

As Radboud university medical center, we have clear goals for the future. We aim to lead the pack in the development of sustainable, innovative, and affordable healthcare: "to have a significant impact on healthcare". The pillars that support this strategy are founded in innovation, personalization and working together in our networks regardless of whether it involves healthcare, education, or research. In terms of healthcare, this means that the patient and their quality of life serve as the basis for all our decisions.

Our goal is to truly get to know the patient. What are their likes and dislikes? What are their unique circumstances? Simply put, we want to know the person, not only the patient. It is only logical that personalized healthcare would lay the groundwork for individualized attention for our 11,000 employees. Care is typically customized at a university medical center. Our employees deserve the same attention that we give to our patients.

Vitality can sometimes be a difficult topic. Healthcare costs are often heavily scrutinized. It is becoming increasingly difficult to keep healthcare affordable, which in turn makes it less accessible. For instance, what exactly does an investment into the power napping area in ICU or the Healthy Professionals program really yield in concrete terms? Our next step is to make this measurable, so that we are standing on solid ground when making these decisions. Nonetheless, our investment in vitality will never come into question. This is an ongoing project without a deadline. At Radboud university medical center, vitality is part of our Human Resource strategy.

We strive to provide exceptional healthcare to our patients, day in and day out. We want to improve diagnoses, treatment methods, and healthcare through our research and train a new generation of doctors and nurses through our education. That can only be accomplished with people who feel challenged and motivated, who love their work, and who strive to do their best each day. By seeing, listening to, and helping each other, we can create the space for the human factor in the workplace.

Open Access This chapter is licensed under the Creative Commons Attribution-NoncommercialNoDerivatives 4.0 International License (http://creativecommons.org/licenses/by-nc-nd/4.0/), which permits any noncommercial use, sharing, distribution and reproduction in any medium or format, as long as you give appropriate credit to the original author(s) and the source, provide a link to the Creative Commons licence and indicate if you modified the licensed material. You do not have permission under this licence to share adapted material derived from this chapter or parts of it.

The images or other third party material in this chapter are included in the chapter's Creative Commons license, unless indicated otherwise in a credit line to the material. If material is not included in the chapter's Creative Commons license and your intended use is not permitted by statutory regulation or exceeds the permitted use, you will need to obtain permission directly from the copyright holder.

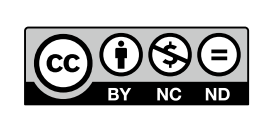

